\title{
Strengthening retina eye care services in Nepal: retina eye care of Nepal project
}

\author{
Arjun Shrestha ${ }^{1 *}\left(\mathbb{D}\right.$, Chunu Shrestha ${ }^{2}$, Pratap Karki ${ }^{3}$, Hara Maya Gurung ${ }^{4}$ and Takeshi Naito ${ }^{5}$
}

\begin{abstract}
Background: Retinal diseases are very difficult to treat. So, early diagnoses and preventions are very important. But, few eye doctors can treat patients with retinal diseases in Nepal. Retina Eye Care of Nepal (RECON) project was designed to strengthen retina eye care services in Nepal.

Methods: RECON was implemented from May 2016 to February 2019 in Nepal. Four Master Eye Doctors (MED) received Training of Trainers (TOT) from Tokushima University, Japan. MEDs developed training materials for different cadres of ophthalmic human resources, enhanced retina eye care facilities, and conducted retina-screening camp in Nepal.

Results: Twenty ophthalmologists, 16 optometrists, 48 ophthalmic assistants and 17 ophthalmic nurses, 76 physicians and 28 health workers were trained in retina care. Eight outreach retina camps were conducted.

Conclusions: The project was a novel approach to strengthen retina services in Nepal. The aim of the project was accomplished with the ultimate benefits to the needy retina patients who otherwise were going to miss the retina services.
\end{abstract}

Keywords: Retina eye care, Nepal, Strengthening

\section{Background}

Recently causes of blindness are changing in Nepal. The number of people blind due to retinal diseases is increasing. Age-related macular degeneration (AMD), diabetic retinopathy (DR), hypertensive retinopathy, and retinal vein occlusion are the major retinal problems in Nepal. As the prevalence of vitreoretinal disorders is increasing with age, it indicates that retinal disorders will be a major public health issue with longevity in future [1].

A rapid assessment of blindness conducted in 2010 had reported posterior segment problems as the second common cause of blindness, after cataract in Nepal [2]. Retinal diseases are very difficult to treat. Results from lowincome countries show that many patients present only when they lose vision in both eyes. Delay in presentation was acknowledged as a significant problem and is often

\footnotetext{
* Correspondence: arjundr@gmail.com

${ }^{1}$ BP Eye Foundation, Hospital for Children, Eye, ENT \& Rehabilitaion Services, Bhaktapur, Nepal

Full list of author information is available at the end of the article
}

due to inadequate primary eye care and to misdiagnosis. Thus, it was highlighted that all ophthalmologists should be trained to recognize and manage retina problems. As blindness from DR is preventable, if caught and treated early, DR provides an excellent opportunity for secondary prevention strategies, such as screenings [3]. So, early diagnoses and preventions are very important.

The projected population of Province 3 and 4 in Nepal were $60,26,626$, and $24,72,494$ respectively in the year $2016[4,5]$. There are altogether 6 tertiary retina care centers in Province 3 and 1 tertiary retina center in province 4 of Nepal to cover that much of the population. But, few eye doctors can treat patients with retinal diseases in Nepal. It is also necessary to train ophthalmic assistants, optometrists, ophthalmic nurses, and other health workers who can assist the treatment of retinal diseases. So, strengthening retina eye care services is very important in Nepal.

Retina Eye Care of Nepal (RECON) project was a joint program of BP Eye Foundation, Kathmandu, Nepal, and Tokushima University, Japan to strengthen 3 retina centers in Province 1 and 1 retina center in province 4. The

C The Author(s). 2020 Open Access This article is licensed under a Creative Commons Attribution 4.0 International License, which permits use, sharing, adaptation, distribution and reproduction in any medium or format, as long as you give appropriate credit to the original author(s) and the source, provide a link to the Creative Commons licence, and indicate if changes were made. The images or other third party material in this article are included in the article's Creative Commons licence, unless indicated otherwise in a credit line to the material. If material is not included in the article's Creative Commons licence and your intended use is not permitted by statutory regulation or exceeds the permitted use, you will need to obtain permission directly from the copyright holder. To view a copy of this licence, visit http://creativecommons.org/licenses/by/4.0/ The Creative Commons Public Domain Dedication waiver (http://creativecommons.org/publicdomain/zero/1.0/) applies to the data made available in this article, unless otherwise stated in a credit line to the data. 
project duration was from May 2016 to February 2019. The purpose of RECON was to strengthen retina eye care services in Nepal by training ophthalmic human resources, enhancing retina eye care facilities, and conducting retina-screening camp.

\section{Methods}

RECON established a unique approach to accomplish its objectives (Fig. 1).

\section{Master eye doctor (MED) training}

Four eye institutes, Hospital for Children, Eye, ENT \& Rehabilitation Services (CHEERS) located at Bhaktapur district, Himalaya Eye Hospital (HEH) located at Kaski district, Nepal Eye Hospital (NEH) and BP Koirala Lions Club of Ophthalmic studies (BPKLCOS), located at Kathmandu district were selected as the partner retina centers. CHEERS and HEH had one retina specialist each and NEH and BPKLCOS had two retina specialists each at the time of project execution. Four Retina specialists, one from each partner retina center of Nepal received one-month Training of Trainers (TOT) in retina care from Tokushima University of Japan in the first year of the project and got a certificate of Master Eye Doctor (MED).MED also received advanced retina training for 2 weeks at Kindai University and the Tokushima University of Japan at the beginning of the 3rd year of the project.

\section{Strengthening of retina Centres}

All partner retina centers already had vitrectomy machines and laser facilities. Vitreoretinal procedures were already in functional states at all retina centers except at CHEERS. Moreover, BPKCLOS and NEH located at the capital city already had residency programs. HEH is located outside of the capital city while CHEERS is a new hospital at Bhaktapur, within close premises of the capital city. The project supported fundus photography machines, ophthalmic ultrasonic imaging, wide-angle viewing system, and cryo machine to these partner eye institutes. MEDs started strengthening of retina clinics with knowledge and skills gained during TOT in retina care from Tokushima University.

\section{Advocacy and retina force networking}

MEDs conducted first continuing medical education (CME) on retina eye care with facilitators and visiting

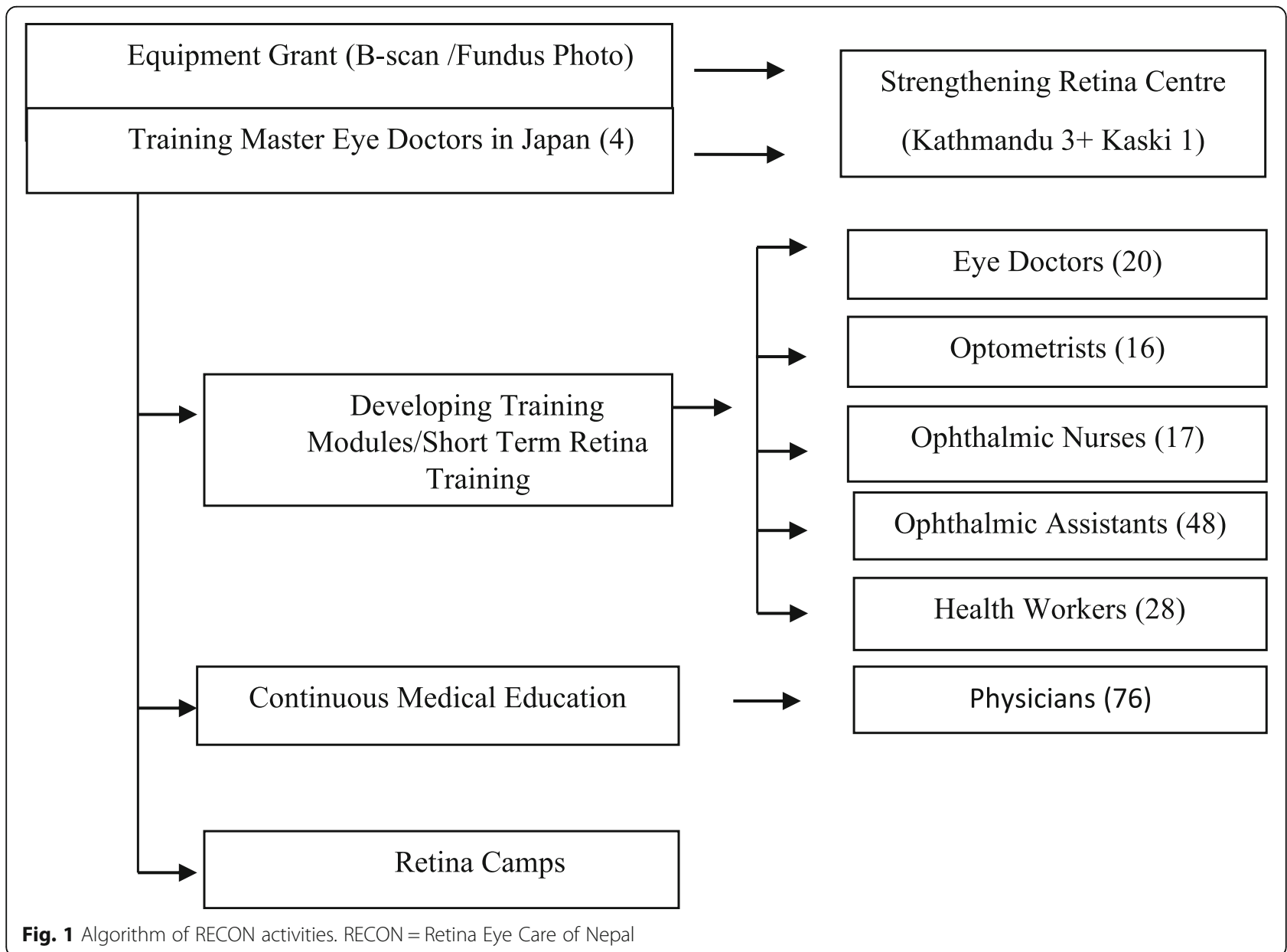


retina experts from Tokushima University to the targeted ophthalmologists with a focus on retina force networking. Second CME was on developing vitrectomy in Nepal.

\section{Training human resources}

These MEDs prepared training materials on retina management for different cadre of ophthalmic human resources including general ophthalmologists, optometrists, ophthalmic assistants, ophthalmic nurses, and female community health volunteers. These MEDs already provided two weeks retina training for ophthalmologists, oneweek training for optometrists, ophthalmic assistants, and ophthalmic nurses from different eye institutes of Nepal. The training included early detection and prompt referral of retinal diseases from the community to the retina training centers.

\section{Retina camps}

Outreach retina camps were conducted outside of base hospitals to target the community who otherwise would not visit the base hospital due to various reasons

Portable fundus camera, binocular and monocular indirect ophthalmoscope with 20 dioptre convex lenses were used to screen the retinal diseases at eye camps. The patients with retinal diseases found at eye camps were sent to the respective retina centers for further treatment. Retina camps were conducted in partnership with local health clubs, municipalities, or nongovernment organizations. Each camp shared the task among different cadres of health care workers including MED, optometrist, ophthalmic nurse and ophthalmic assistant. MED performed fundoscopy and advised for further treatment, optometrist performed fundus photography, ophthalmic nurses helped in counseling and ophthalmic assistant helped in taking vision, pupil dilation, and history taking.

\section{Results}

Table 1 shows the number of vitreo retina procedures by all 4 retina centers before and during the project period. There were no vitreoretinal procedures performed at CHEERS before the RECON project. The vitreo retina procedures were performed more in already established partner eye institutes; NEH and BPKLCOS. NEH and BPKCLOS are located in the capital city, already had two retina specialists and the experiences of residency programme. All retina centers are doing good performance every year after enrolling in the RECON project. These retinal procedures were invariably performed by the retina specialists of the respective retina centers. Advocacy campaigns and retina camps were held as shown in Table 2.

\section{Discussion}

Recently, retinal disease is also regarded as a public health concern in the developing world. There have been improved and cost-effective treatment options available for retinal problems even in a developing world. However, a significant challenge still is the shortage of skilled human resources. There is an observed and felt need for more ophthalmic health force with subspecialty training in retinal disease who can train future generations of eye workers in this mid and low-income countries [6].

A significant barrier was the practice of setting up a screening system without adequate treatment facilities being in place [3]. In our case, all retina centers already had vitrectomy machines, laser facility, and optical coherence tomography. RECON executed skill enhancement, trained, and retrained MEDs of Nepal in capacity building. CME

Table 1 Vitreo retinal procedures

\begin{tabular}{|c|c|c|c|c|c|c|}
\hline \multirow[b]{2}{*}{ Vitreo Retinal Surgeries } & \multicolumn{2}{|c|}{ Before RECON } & \multicolumn{3}{|c|}{ During RECON } & \multirow[b]{3}{*}{ CHEERS } \\
\hline & Year 1 & Year 2 & Year 1 & Year 2 & Year 3 & \\
\hline & 0 & 0 & 18 & 147 & 211 & \\
\hline & 51 & 102 & 160 & 167 & 260 & BPKLCOS \\
\hline & 44 & 96 & 210 & 314 & 349 & NEH \\
\hline & 14 & 27 & 38 & 45 & 48 & $\mathrm{HEH}$ \\
\hline \multirow[t]{4}{*}{ Intravitreal injections } & 0 & 0 & 64 & 301 & 402 & CHEERS \\
\hline & 0 & 93 & 374 & 370 & 583 & BPKLCOS \\
\hline & 72 & 188 & 367 & 773 & 1544 & NEH \\
\hline & 305 & 314 & 411 & 686 & 1088 & $\mathrm{HEH}$ \\
\hline \multirow[t]{4}{*}{ Retinal Lasers } & 0 & 0 & 17 & 113 & 123 & CHEERS \\
\hline & 65 & 79 & 178 & 290 & 336 & BPKLCOS \\
\hline & 55 & 73 & 168 & 250 & 448 & NEH \\
\hline & 25 & 35 & 78 & 99 & 105 & $\mathrm{HEH}$ \\
\hline
\end{tabular}


Table 2 Advocacy and Retina camps

\begin{tabular}{ll}
\hline No of CMEs & 2 \\
No of Retina Camps & 8 \\
No of Retina patients screened at the camp & 627 \\
No of IEC materials distributed & 2000 \\
\hline $\begin{array}{l}\text { No Number, CME continuous medical education } \\
\text { IEC information, education \& communication }\end{array}$ &
\end{tabular}

helped in advocacy campaign and retina forces networking. All the trainees, eye doctors, optometrists, ophthalmic assistants, ophthalmic nurses, and physicians were providing education to retina patients about the importance of retina check-up and referring them in need to our retina care centers.

The general practitioners and physicians are often the first medical personals to see the patients with diabetes. There are varying levels of awareness about diabetic retinopathy among physicians. This is very crucial as they are the ones referring patients with diabetes to ophthalmologists. It is not surprising to see an unsatisfactory level of knowledge and awareness of physicians about the importance of diabetic retinopathy evaluation. Physician's low level of awareness about diabetic retinopathy is found even in resource-rich settings, and further training is recommended [7-9].

Most Eye camp is widely practiced in all over Nepal. To add the retinal disease screening at eye camps is very useful for the prevention of retinal diseases. Retina camps were the means of eye health education, eye examinations, fundus photography to patients in our project.

The conclusion from Bhakapur retina study in Nepal highlighted the real world scenario about retinal diseases in Nepal. The high prevalence of retinal diseases, low awareness on major blinding retinal diseases in the population and high risk groups warrants the prompt attention for awareness campaigns, retinal diseases screening, using allied ophthalmic personnel and allied medical personnel using fundus cameras, proper referral network to tertiary eye hospitals, cross referral with the physician for diseases like diabetes, and hypertension and facilities for treatment of these diseases are required for the prevention of avoidable blindness from these major retinal disorder [10].

In our retina camps, apart from direct beneficiaries who got free consultation in retina camps, there were many indirect beneficiaries in the community. Awareness of diabetic and hypertensive retinopathy and other retinal diseases were the main aims of retina camp. This is a good step of advocacy for early detection and prompt treatment to prevent retina related visual blindness in Nepal.

The comprehensive campaigns are necessary to promote increased awareness in a community by involving people from various walks of life in collaboration with community eye centres and eye hospitals. Improving awareness will help in early detection of diseases and reduction in visual impairment and blindness [11].

\section{Conclusions}

RECON was a novel approach to strengthen retina services in Nepal. The aim of the project was the ultimate benefits to the needy retina patients who otherwise were going to miss the retina services. There was a strengthening of retina eye care of all these retina centers. The project focused on the training retina workforces, enhancing retina care by easy access and improved services and awareness to even grass root level in the community by conducting retina-screening camp. We recommend further similar type of strategy in different provinces of Nepal to combat retinal-related blindness in the future.

\section{Abbreviations \\ AMD: Age related macular degeneration; BPKLCOS: BP Koirala Lions Club of Ophthalmic Studies; CHEERS: Hospital for Children, Eye, ENT \& Rehabilitation Services; HEH: Himalayan Eye Hospital; NEH: Nepal Eye Hospital; CME: Continuous medical education; DR: Diabetic retinopathy; IEC: Information education and communication; MED: Master Eye Doctor; RECON: Retina Eye Care of Nepal; TOT: Training of Trainers}

\section{Acknowledgements}

We would like thank Prof. Madan Prasad Upadhyay, who guided us in various ways from the very beginning to the end of the project and even in writing the manuscript. We would also like to thank Mrs. Miki Upreti, program co-ordinator and Mrs. Pujan Khanal program officer of RECON project for their great supports in execution of the program.

\section{Authors' contributions}

AS designed the study, collected data, undertook the analysis and wrote the manuscript; CS assisted in study design, data collection, wrote and revised the manuscript; PK assisted in study design, data collection and revised the manuscript; HMG collected data and reviewed the manuscript; TN assisted in study design and reviewed the manuscript. All authors reviewed and approved the final manuscript.

\section{Funding}

RECON project was funded by Japanese International Cooperation Agency (JICA) and Tokushima University, Japan. Funding agency had no role in the design or conduct of the study, or in the decision to submit the article for publication.

\section{Ethics approval and consent to participate}

We adhered to the tenet of the Helsinki declaration. The permission to publish project output was approved by the project implementing organization, BP Eye Foundation. The local research committee waived the need for informed consent in this retrospective study (Reference No.: 522076/077).

\section{Consent for publication}

Consent of publication is "not applicable" to participants.

\section{Competing interests}

The authors declare that they have no competing interests.

\section{Author details}

${ }^{1}$ BP Eye Foundation, Hospital for Children, Eye, ENT \& Rehabilitaion Services, Bhaktapur, Nepal. ${ }^{2}$ Nepal Eye Hospital, Kathmandu, Nepal. ${ }^{3}$ BP Koirala Lions Club of Ophthalmic Studies, Kathmandu, Nepal. ${ }^{4}$ Himalaya Eye Hospital, Kaski, Nepal. ${ }^{5}$ Department of Ophthalmology, Institute of Biomedical Sciences, Tokushima University Graduate School, Tokushima, Japan. 
Received: 2 June 2020 Accepted: 21 October 2020

Published online: 27 October 2020

\section{References}

1. Thapa SS, Thapa R, Paudyal I, et al. Prevalence and pattern of vitreo-retinal diseases in Nepal: the Bhaktapur glaucoma study. BMC Ophthalmol. 2013; 13:9. https://doi.org/10.1186/1471-2415-13-9.

2. Sapkota YD. Epidemiology of blindness in Nepal: 2012. Nepal Netra Jyoti Sangh: Publisher; 2013

3. Shah S. Blindness and visual impairment due to retinal diseases. Commun Eye Health. 2009;22(69):8-9.

4. National Population and Housing Census 2011.Population Projection 20112031.Volume 08, NPHC 2011. Published by central Bureau of statistics in 2014. www.cbs.gov.np.

5. Nepal: Administrative division. https:/www.citypopulation.de/php/nepaladmin.php. Accessed on 2017.10.07.

6. Yorston D. Retinal diseases and VISION 2020. Commun Eye Health. 2003; 16(46):19-20.

7. Pradhan E, Khatri A, Tuladhar J, Shrestha D. Diabetic Eye Disease Related Knowledge, Attitudes and Practices among Physicians in Nepal. J Diabetes Endocrinol Assoc Nepal. 2(2):26-36. https://doi.org/10.3126/jdean.v2i2.22359.

8. Khandekar R, Shah S, Lawatti J. Retinal examination of diabetic patients: knowledge, attitudes and practices of physicians in Oman. East Mediterr Heal J. 2008;14(4):850-7.

9. Kaliyaperumal K. Knowledge, Attitude and Practice Study on Diabetes and Diabetic Retinopathy among Medical Practitioners in Southern India. Commun Ophthalmol. 2006;Vl:2.

10. Thapa R. Retinal diseases pattern and prevention of blindness in Nepal. Acta Scientific Ophthalmol. 2019;2(6):11-2.

11. Thapa R, Bajimaya S, Paudyal G, et al. Population awareness of diabetic eye disease and age related macular degeneration in Nepal: the Bhaktapur retina study. BMC Ophthalmol. 2015;15:188. https://doi.org/10.1186/s12886015-0175-z.

\section{Publisher's Note}

Springer Nature remains neutral with regard to jurisdictional claims in published maps and institutional affiliations.

Ready to submit your research? Choose BMC and benefit from:

- fast, convenient online submission

- thorough peer review by experienced researchers in your field

- rapid publication on acceptance

- support for research data, including large and complex data types

- gold Open Access which fosters wider collaboration and increased citations

- maximum visibility for your research: over $100 \mathrm{M}$ website views per year

At BMC, research is always in progress.

Learn more biomedcentral.com/submissions 